\title{
COVID-19: Positive Impacts and Way Forward
}

\author{
Ayushi Sharma \\ Medical Intern, Department of Community Medicine, Jawaharlal Nehru Medical College, DattaMeghe Institute \\ of Medical Sciences (DU), SawangiMeghe, Wardha, Maharashtra, India. \\ Email:ayushishrma10@gmail.com \\ Type of Article: Review \\ Conflict of Interest: None \\ Funding: DMIMS \\ Ethical Approval: IEC, DMIMS, Wardha.
}

\begin{abstract}
BACKGROUND

COVID-19 or coronavirus disease 2019 has penetrated all across the world. There are some positive connotations which needs to be analyzed in order gain some insight.
\end{abstract}

\section{SUMMARY}

COVID-19 is a dreaded disease outbreak turned pandemic of the century which have huge negative impact on the lifestyle of the human population. The devastation that caused by the disease outbreak is tremendous and may take years to heal. But there is other side of the story. Many unexpected effects were seen after mitigation measures were enforced. The effects that we experience would have taken years if such drastic measures were not undertaken. From cleaner environment to reduction in traffic accidents, from positive behavioral changes to accelerated science and technology actions there are many positives which are attached to COVID-19 effects.

\section{CONCLUSION}

Although these measures cannot be continued for long term another sustainable strategy and policies are needed in order to maintain the gains that we got unexpectedly. More study needs to be done in order to plan about how these effects can be sustained.

Keywords: covid-19, positive impact, environment, traffic accidents, behavioral changes, sustainability.

\section{INTRODUCTION}

Coronavirus disease 2019 or COVID-19 is the lethal disease caused by SARS-COV-2 commonly known as novel coronavirus.(1) The disease has been proving deadly and already spread to almost all parts of the world. No other natural calamity or disease outbreak has been recorded to take millions of people as case fatalities. As of January 8, 2021, 88,222,239 infection cases are registered which are of COVID19 and 1,904,122 people lost their lives due to COVID-19 related complications(2). The case fatality is reaching the two million mark which is extremely unfortunate and distressing.
Seeing such havoc wreaked by the COVID-19, World health organization upgraded it from public health emergency of international concern (PHEIC) to pandemic on March 11, 2020, which was first of its kind event since the inception of the $\mathrm{WHO}(3)$. United states of America, India, Brazil, Russian federation, France and united kingdom topped the list which together accounts for more than half of the infection cases and deaths due to COVID19(4). Also the problem became graver as new mutated strain of the novel coronavirus has been reported from United Kingdom and South Africa(5). The new strain is supposedly sixty to seventy percent more virulent than the current 
strain. Many countries are again resorting to lockdown like measures as the news about mutated strain spreads scare. As all negative news are attached with the COVID-19, there has been hidden positive side of the pandemic as well. COVID-19 induced lockdown was resulted in having cleaner environment and increased biodiversity which indicates that nature got some breather from corroding human activity(6). Lesser traffic accidents were seen and science and technology got accelerated as a result many pleasant results were unfolded. In this article these positive impact of COVID-19 has been comprehensively overviewed.

\section{POSITIVE SIDE OF THE COIN}

COVID-19 has so far spread in more than two hundreds countries and territories and infecting more than eighty million people around the world. More than one and half million people lost their lives while battling with the lethal coronavirus disease 2019. Many aspects of our lives were affected negatively and there was widespread loss of livelihood and jobs. People even finding it difficult to meet the daily food demand as most of the daily wagers lost their jobs. This has created a very grim picture about the current scenario. Also the uncertainty attached to the COVID-19 pandemic and no clue about the sure shot treatment has been adding to the woes of already wounded people. Physical and mental impacts were huge and there were all negativity around the world. Extreme negative connotation is attached to the COVID-19 pandemic which devastated the lives of the people. And which is true to considerable extent. But there are always two sides of the coin telling another side of the story. We know that the negative side is way too heavier than other side. But there is some silver lining to this whole pandemic situation. Various unexpected yet positive impact has also been seen in past several months which were totally out of the bound of human capacity. These impacts were always thought of in normal times but lazy attitudes towards achieving these goals has always contributed towards never achieving these goals. Yet they were always dreamt of only and never seriously acted upon. But the COVID-19 pandemic induced several mitigation measures and other steps in dealing with the lethal pandemic has resulted in some unexpected yet desired effects which needs to be continued deliberately even after weaning of the effects of these measures. It shows that no matter how negative the event is occurred there will always be some brighter side to it so that people can look upon and get a sigh of relief at least for that moment(7).

\section{CLEANER ENVIRONMENT}

As the inception of the pandemic happened in Wuhan city of the Hubei province in China, governmental agencies and health authorities started to research on the suspected virus that is killing many people in china. Initially thought of unknown pneumonia was later found out to be novel coronavirus or SARS-COV-2 which is causing coronavirus disease 2019. The higher transmissibility of the disease and its lethal nature forced various governments around the countries to take some coercive action in order to curb the spread of the virus. This has resulted in the imposition of the lockdown and movement restrictions as non-pharmacological interventions (NPI's). This blanket measure around the world was supposed to curb the spread and break the chain of the viral transmission by keeping people apart mostly in their residence. The intensity and compliance of the lockdown may vary across different countries around the world as the governing structure varies tremendously but the purpose was same that is to contain the disease outbreak. The initiation of the lockdown measure was done by the country that faced first spurt of cases that is China, then it was followed by many countries as the case infection spread through the countries. Also countries along 
with governmental authorities and health care fraternity saw no other feasible option at that time as the disease has hit the humanity for the very first time(8). No other precedent was available to follow. The effect of this was large percentage of the population inhabiting the earth was made to be at home or their respective places. This was the exception for the essential services providers such as law enforcement agency personals, doctors and other allied health care professionals and several other professionals providing essential services. This has resulted in exponential fall in the movement of people around their respective city. Almost no to few vehicles were roaming on the road and that too of essential services providers. Unprecedented decline in pollution level was seen and cleaner air can be experienced automatically. People were felling the pleasant weather which was ruined by constant pollution emitted by the vehicles on roads. Vehicular emission has major chunk in the environmental pollution figures and governments around the world were trying to minimize the pollution by adopting electronic vehicle policies as they do not emit harmful effluents. Also due to movement restrictions and prohibition of any activity that is going to result in gathering of many people, industries and various companies were forced to shut down or scale down the output so that safe minimum number can be maintained in the workplace. This closure of industrial units also contributed to the cleaner air as many harmful pollutants are emitted from the industries. This difference in air quality was felt in especially those countries who are reeling under the pressure of pollution levels. The Asian countries like India, China who harbors major chunk of human civilization and have growth potential which ultimately industrial countries felt huge reduction in pollution levels. In fact the India, harbors almost many cities in the top ten polluting cities list. According to World air quality report 2019 Indian, the second most populous country on earth, stands at fifth place while the Indian city of Ghaziabad, a satellite town of national capital region Delhi, topped the list with highest degree of pollution. Ghaziabad is a major information and technology hub and harbors various IT parks employing hundreds of thousands of white collar workers who generally commutes with their personal vehicle mostly cars. This concludes why this city of India has highest pollution levels. But as lockdown was announces and these It folk were made to sit at home and work from their made traffic considerably less and also reduction this polluted city. The most dreaded particulate matter 2.5 (PM 2.5) pollutant was reduced drastically by almost 85.1 percent(9). Which was never believed to be achieved in normal scenario. This decrease in levels of PM 2.5 levels was compared to three months before the lockdown was announced that is January 2020. There was 46.1 percent decrease in terms of previous year and same month that is March in which most of the countries imposed these lockdown restrictions. Various pollutants such nitrogen dioxide, Sulphur dioxide, particulate matter 10 (PM 10) were also found to be reduced. PM 10 level was lowered by 50.8 percent and nitrogen dioxide was reduced by 48.7 percent and sulphur dioxide values was reduced by 14.3 percent as Compared to the January 2020 values in which no lockdown was imposed. Space agencies like national aeronautics and space administration (NASA) and European space agency (ESA) taken images from satellites shows the more clearer image from space that was blocked by smog and pollution. The pollutants are already causing various lung related disease(10).

\section{COVID-19 AND BIODIVERSITY AS A WHOLE}

The lockdown induced by COVID-19 has its impact on Biodiversity and wild flora and fauna too. Due to lockdown and 
movement restrictions, large amount of human interference in nature has been curbed artificially, but it has shown some marvelous results which would otherwise be never seen. Animals were seen roaming around empty streets like they were there to reclaim what was theirs and humans snatched it away only to destroy it. They were amazed that where is that creature who on daily basis destroys out habitats and livelihoods. Large amount of illegal feeling of trees for timber and other purposes were averted as movement restrictions were enforced. Poaching was certainly at least for short duration of time was stopped and nature gets some breather to heal itself. Sand mafia were not on duty to illegally swoop the floor of the river disturbing the river course as well as the marine life there. Also the level of water pollution was drastically reduced as various industries which are generally near any major river, were closed and less effluents were thrown out in river. This water is the same water which fulfills the need of the drinking water. Therefore people were getting cleaner water. Cremation and ritualistic activities near water body or anywhere almost absent and this further reduced the pressure of the pollution on the water body. This has cascading effects on marine life as they got some time to overcome the damage done by increasing human activity. The biological oxygen demand (BOD) levels are the indicators of water quality and tells how marine life is facing the heat of the pollution. Increased BOD levels means the water is more polluted and decreased means water is comparatively cleaner. After lockdown was announced, Yamuna, Major River near New Delhi, capital city of India, saw BOD levels decreased and cleaner starches of Yamuna than before(11).

\section{REDUCTION IN ROAD TRAFFIC ACCIDENTS}

COVID-19 induced lockdown and movement restrictions and the fear of viral infection which Is deadly and lethal and no one wants to catch the infection has been successful in reducing the overall accident rate due to road traffic. Each year more than a million people lose their life behind road traffic accidents and many of them get injures. Also loss of property is also considerably high. Various road safety awareness campaigns were run by various governmental agencies and international agencies to create awareness among commuters to follow rules and do not breach them. High penalty along with jail term were inserted after various amendments in to the law for creating a fear about the law. But these activities was not giving results. As lockdown was announced and more and more people were left at home and there was ban on going outside, naturally vehicles on road were reduced and so do the accidents related to them. A study observation conducted in north eastern Spain on effects of COVID-19 induced lockdown and road traffic accidents(12). It was found in the study that road accidents fell by 76 percent than the previous month that is February which was allowing normal traffic. The fall as compared to previous year but same month has crossed three quarters and stands at whooping 76 percent. Also the lockdown has induced considerable amount of loss of livelihood and job losses. It also means reduction in income levels resulting in lowering the consumption of psychotropic substances like alcohol, tetra hydro cannabinol (THC) which intoxicates the body and affects cognitive and neural and motor control. If a person drives in inebriated state then the chance of risking itself as well as others lives are at huge risk. These high risk vehicle drivers group were made to sit at home and the hazard was reduced. In addition people became aware about the physical fitness and its importance. Therefore many people resorted to cycling for health and also run some small errands near home with the help of bicycle. This not only helped in keeping people fit and 
healthy and reducing levels of pollution but also reduced the accidents on roads as vehicles were reduced. In some countries dedicated lanes for bicycle help in commuting which must be adopted by all the countries(13).

\section{COVID-19 AND OTHER COMMUNICABLE DISEASE}

COVID-19 has brought about several good change that is keeping them safe from other disease too. For example protection from coronavirus disease 2019 includes maintain minimum safe distance, hand hygiene, wearing masks and keeping your body fit. This has also raised the awareness levels among people about other communicable disease such as asthma, tuberculosis and so on. These disease were also undetected and needs to be detected in order to eradicate them. According to sustainable development goals which are due to be achieved by 2030 , tuberculosis must be eradicated. This pandemic has provided the opportunity in disguise to raise awareness about any communicable disease which can be cured. Many patient while screening for COVID-19 are diagnosed for any other chronic disease which were they unknown of. Therefore more such checkups are necessary in order to cash in the disguised opportunity which COVID-19 has provided. Hygienic habits are all beneficial in any scenario and will give long term benefits(14).

\section{BEHAVIORAL CHANGES IN COVID- 19}

The unprecedented nature of the pandemic and the lethal consequence seen by many in terms of case fatality numbers has shook the world from inside. People felt that in order to survive the calamity of such large scale, necessary changes are needed to be done in the lifestyle. Mitigation measures also included certain daily habits which were relic of the past. But their effectiveness and benefits were seen by many and were readily adopted in order to safeguard oneself. Lockdown was induced by COVID-19 mitigation measures and it made people sit at home. People were spending more time with themselves and realizing about their good and bad choices about their lives. Many understood how fragile is the system and building resilience is the only mantra to successfully completes the journey on earth. Many resorted to quick thinking and started to quit bad habits such as smoking and drinking. Lockdown already provided chance with shop closed for almost couple of months(15). It acted as a wisdom push to those who always wanted to quit but never got courage. Many tangled relationships were rebuilt and new avenues were open. People reflected upon their lives and started to think about the real meaning of life. Some started yoga and meditation to keep the body, mind and soul in sync. Some started or raised their philanthropic activity as simplicity is the ultimate sophistication. The plight of migrant laborers in the country of India were seen by many and many provided them with shelter and food along their way to home. People were sensitized about the current pandemic situation. Also they learn to live a minimalistic life which is the most sustainable and nest option for every human being. Also daily activities like hand hygiene were helping disease mitigation all along these times. Sanitization after every touch creates a healthy ecosystem coupled with mask and physical distancing(16).

\section{ADVANCEMENT IN SCIENCE AND TECHNOLOGY}

COVID-19 brought tremendous catastrophic change of events which mandates huge research and development as the coronavirus strain was totally new and there was no idea about how it will unfold. Unfortunately the effects are seen even today and whole world still bearing the brunt of the COVID-19. This results in acceleration in the field of medicine and pharmaceuticals among other engineering 
branches to jointly tackle the pandemic. As of January 2021, vaccine roll out is in its final phase and dry runs of the vaccination program as a mock drill was done in many countries. Many countries even started to vaccinate the high risk groups such as elderly and health care professionals. The vaccine was ready in record time as no other vaccine was approved within one year of the disease outbreak. This was only possible due to high level of cooperation among various branches of sciences and applied sciences and hard work of people who were toiling day and night to get the vaccine approved and safe for the people. Extreme innovative activities was seen in field of biomedical engineering and allied branches. From low cost ventilators to $3 \mathrm{~d}$ printed face shields, everyone was there to contribute to the good work. For the first time portable COVID-19 care facility with intensive care unit structure was made available which was very easy to move. Cheap yet effective diagnostic kit were made in order to test people fast. For example in India, there was only one testing and genomic center that were testing sample which were situated in the city of Pune. But accelerated health spending which was long overdue made possible that now each and every district has minimum three to four testing centers and many diagnostic and treatment facility. Science and technology progress was also exponential and these innovation will give benefits to many years to come(17). Many studies related to positive effects of Covid are available (18-22). Few of the related studies were reviewed (23-26).

\section{CONCLUSION}

Many positive gains were knowingly or unknowingly achieved but the real challenge lies in sustaining those gains. Traffic accidents are hard to maintain at lockdown level but more awareness can be created in order to sensitize and aware people of the rules. Environment was long being reeling under pressure of extensive encroaching and destroying activities of humans. The pandemic has shown that nature can strikes back whenever it wants. Science and technology gains are here to stay with us and necessary lessons should be learnt from the situation. After sustainable interaction between human and nature and balance between environment and development is the ultimate key to succeed as coexisting species.

\section{REFERENCES}

1. Dushyant Bawiskar, Pratik Phansopkar, Ayurva Vilas Gotmare. COVID-19 Facets: Pandemics, Curse and Humanity. Int J Res Pharm Sci. 2020 Aug 6;11(SPL1):385-90.

2. COVID-19 Map [Internet]. Johns Hopkins Coronavirus Resource Center. [cited 2021 Jan 8]. Available from:

https://coronavirus.jhu.edu/map.html

3. WHO Director-General's opening remarks at the media briefing on COVID-19 - 11 March 2020.pdf.

4. WHO Coronavirus Disease (COVID19) Dashboard [Internet]. [cited 2021 Jan 8]. Available from: https://covid19.who.int

5. Wise J. Covid-19: New coronavirus variant is identified in UK. BMJ [Internet]. 2020 Dec 16 [cited 2020 Dec 23];371:m4857. Available from: https://www.bmj.com/content/371/b mj.m4857

6. The Lancet null. India under COVID-19 lockdown. Lancet Lond Engl. 2020 25;395(10233):1315.

7. Li L, Li Q, Huang L, Wang Q, Zhu $\mathrm{A}, \mathrm{Xu} \mathrm{J}$, et al. Air quality changes during the COVID-19 lockdown over the Yangtze River Delta Region: An insight into the impact of human activity pattern changes on air pollution variation. Sci Total Environ 
[Internet]. 2020 Aug 25 [cited 2020 Oct 26];732:139282. Available from: http://www.sciencedirect.com/science /article/pii/S0048969720327996

8. Chauhan A, Singh RP. Decline in PM2.5 concentrations over major cities around the world associated with COVID-19. Environ Res [Internet]. 2020 Aug 1 [cited 2020 Oct 26];187:109634. Available from: http://www.sciencedirect.com/science /article/pii/S0013935120305272

9. Ranjan AK, Patra AK, Gorai AK. Effect of lockdown due to SARS COVID-19 on aerosol optical depth (AOD) over urban and mining regions in India. Sci Total Environ [Internet]. 2020 Nov 25 [cited 2020 Oct 26];745:141024. Available from: http://www.sciencedirect.com/science /article/pii/S0048969720345538

10. Lokhandwala S, Gautam P. Indirect impact of COVID-19 on environment: A brief study in Indian context. Environ Res [Internet]. 2020 Sep 1 [cited 2020 Oct 26];188:109807. Available from: http://www.sciencedirect.com/science /article/pii/S0013935120307027

11. Kamdi PS, Deogade MS. The hidden positive effects of COVID-19 pandemic.Int $\mathbf{J}$ Res Pharm Sci [Internet]. 2020 Aug 4 [cited 2020 Oct 26];11(SPL1):276-9. Available from:

https://pharmascope.org/ijrps/article/ view/2712

12. Oguzoglu U. COVID-19 Lockdowns and Decline in Traffic Related Deaths and Injuries. 2020;19.

13. Qureshi AI, Huang W, Khan S, Lobanova I, Siddiq F, Gomez CR, et al. Mandated societal lockdown and road traffic accidents. Accid Anal Prev [Internet]. 2020 Oct [cited 2020
Nov 9];146:105747. Available from: https://www.ncbi.nlm.nih.gov/pmc/ar ticles/PMC7475733/

14. Anser MK, Yousaf Z, Khan MA, Sheikh AZ, Nassani AA, Abro MMQ, et al. Communicable Diseases (Including COVID-19)-Induced Global Depression: Caused by Inadequate Healthcare Expenditures, Population Density, and Mass Panic. Front Public Health [Internet]. 2020 [cited 2020 Nov 9];8. Available from: https://www.frontiersin.org/articles/1 0.3389/fpubh.2020.00398/full

15. The positive effects of COVID-19 and the social determinants of health: all in it together? 2020 Dec 14 [cited 2020 Dec 23];m1785. Available from:

https://www.bmj.com/content/369/b mj.m1785/rr

16. Long VJ, Liu JC. BEHAVIORAL CHANGES DURING THE COVID19 PANDEMIC: RESULTS OF A NATIONAL SURVEY IN SINGAPORE. medRxiv [Internet]. 2020 Aug 7 [cited 2020 Dec 23];2020.08.06.20169870. Available from:

https://www.medrxiv.org/content/10. 1101/2020.08.06.20169870v1

17. Science, technology and innovation efforts to address COVID19 | UNCTAD [Internet]. [cited 2021 Jan 8]. Available from: https://unctad.org/topic/commissionon-science-and-technology-fordevelopment/covid-19.

18. Anjankar Ashish, P., P. Anjankar Vaibhav, J. Anjankar Anil, and K. Lata. "Positive Aspects of Covid 19 Pandemic: A Blessing in Disguise." International Journal of Research in Pharmaceutical Sciences 11, no. Special Issue 1 (2020): 187-91. 
https://doi.org/10.26452/ijrps.v11iSPL 1.2371

19. Borage, S., and P. Shelotkar. "Positive Effects of Covid-19 on Earth." International Journal of Research in Pharmaceutical Sciences 11, no. Special Issue 1 (2020): 234-38. https://doi.org/10.26452/ijrps.v11iSPL 1.2704 .

20. Kamdi, P.S., and M.S. Deogade. "The Hidden Positive Effects of Covid-19 Pandemic." International Journal of Research in Pharmaceutical Sciences 11, no. Special Issue 1 (2020): 276-79. https://doi.org/10.26452/ijrps.v11iSPL 1.2712 .

21. Srivastava, R., N. Rathi, N. Thosar, S. Baliga, M. Khubchandani, V. Mohite, J. Mehta, and R. Waykar. "Contemporary Treatment Modalities for the Management of SARS-CoV-2 Positive Patients: An Overview." International Journal of Research in Pharmaceutical Sciences 11, no. Special Issue 1 (2020): 839-46. https://doi.org/10.26452/ijrps.v11iSPL 1.3090 .

22. Sonone, A., A. Hande, M. Gawande, and S. Patil. "Sickle Cell Individuals Are Less Vulnerable for Corona Virus Disease 2019-an Enigma." International Journal of Research in Pharmaceutical Sciences 11, no. Special Issue 1 (2020): 1015-17. https://doi.org/10.26452/ijrps.v11iSPL 1.3427 .

23. Sonone, A., A. Hande, M. Gawande, and S. Patil. "The Mystery of Low COVID-19 Mortality Rate in India." International Journal of Research in Pharmaceutical Sciences 11, no. Special Issue 1 (2020): 1180-82. https://doi.org/10.26452/ijrps.v11iSPL 1.3586.

24. Chawla, D., P. Wagh, S. Ali, U. Jadhav, and B. Ghewade. "Impact of COVID 19 Pandemic on Tuerculosis." International Journal of Research in Pharmaceutical Sciences 11, no. Special Issue 1 (2020): 1084-88.
https://doi.org/10.26452/ijrps.v11iSPL 1.3533 .

25. Gaidhane, S., N. Khatib, Q.S. Zahiruddin, A. Gaidhane, S. Telrandhe, and P. Godhiwal. "Depression, Anxiety and Stress among the General Population in the Time of COVID-19 Lockdown: A Cross-Sectional Study Protocol." International Journal of Research in Pharmaceutical Sciences 11, no. Special Issue 1 (2020): 360-64. https://doi.org/10.26452/ijrps.v11iSPL 1.2726 .

26. Gaidhani, K.V., and S.P. Chalakh. "COVID-19 Is a Janapadodwans Vyadhi in Ayurveda-a Review." International Journal of Research in Pharmaceutical Sciences 11, no. Special Issue 1 (2020): 1363-66. https://doi.org/10.26452/ijrps.v11iSPL 1.3642 . 